\title{
X-ray Absorption and Raman Spectroscopy Studies of Molybdenum Environments in Borosilicate Waste Glasses
}

\author{
David A. McKeown*, Hao Gan, and Ian L. Pegg, \\ Vitreous State Laboratory, The Catholic University of America, \\ 620 Michigan Ave, N.E., Washington, D.C. 20064 \\ * corresponding author: \\ Phone: (202) 319-5226, FAX: (202) 319-4469; e-mail: davidm@,vsl.cua.edu
}

\begin{abstract}
Mo-containing high-level nuclear waste borosilicate glasses were investigated as part of an effort to improve Mo loading while avoiding yellow phase crystallization. Previous work showed that additions of vanadium decrease yellow phase formation and increases Mo solubility. X-ray absorption spectroscopy (XAS) and Raman spectroscopy were used to characterize Mo environments in HLW borosilicate glasses and to investigate possible structural relationships between Mo and V. Mo XAS spectra for the glasses indicate isolated tetrahedral $\mathrm{Mo}^{6+} \mathrm{O}_{4}$ with Mo-O distances near $1.75 \AA$. V XANES indicate tetrahedral $\mathrm{V}^{5+} \mathrm{O}_{4}$ as the dominant species. Raman spectra show composition dependent trends, where Mo-O symmetrical stretch mode frequencies $\left(v_{1}\right)$ are sensitive to the mix of alkali and alkaline earth cations, decreasing by up to
\end{abstract}


$10 \mathrm{~cm}^{-1}$ for glasses that change from $\mathrm{Li}^{+}$to $\mathrm{Na}^{+}$as the dominant network-modifying species. This indicates that $\mathrm{MoO}_{4}$ tetrahedra are isolated from the borosilicate network and are surrounded, at least partly, by $\mathrm{Na}^{+}$and $\mathrm{Li}^{+}$. Secondary $v_{1}$ frequency effects, with changes up to 7 $\mathrm{cm}^{-1}$, were also observed with increasing $\mathrm{V}_{2} \mathrm{O}_{5}$ and $\mathrm{MoO}_{3}$ content. These secondary trends may indicate $\mathrm{MoO}_{4}-\mathrm{MoO}_{4}$ and $\mathrm{MoO}_{4}-\mathrm{VO}_{4}$ clustering, suggesting that $\mathrm{V}$ additions may stabilize $\mathrm{Mo}$ in the matrix with respect to yellow phase formation. 


\section{Introduction}

Molybdenum is a fission product that is present in spent nuclear fuels and in high level waste (HLW) streams resulting from nuclear fuel reprocessing. Higher concentrations of molybdenum are typically present in HLW streams from commercial fuel reprocessing as compared to defense HLW streams due to the generally higher burn-up for the former. HLW streams are typically immobilized by vitrification. The presence of significant amounts of molybdenum can lead to the formation of a molybdate salt phase ("yellow phase") that separates from the glass melt during vitrification [1-11]. This salt phase has variable composition but, in addition to Mo, typically also incorporates $\mathrm{Na}, \mathrm{Li}, \mathrm{Cs}, \mathrm{Ca}, \mathrm{Ba}$, as well as $\mathrm{Cr}, \mathrm{S}$, and $\mathrm{Tc} ; \mathrm{Cr}$ as chromate imparts the yellow color. These salts are often low-temperature melting, very fluid at typical melter operating temperatures, of variable density depending on their composition, and have higher aqueous solubility than the glass. Consequently, these salts are undesirable from both melter operations and product quality perspectives, such that yellow phase formation can become the primary factor that limits waste loading in the HLW glass product. In previous work, various strategies were investigated to control yellow phase formation and allow significantly higher waste loadings to be achieved [8-11]. In one of those strategies, the glass formulations were modified to include vanadium, which was found to increase the solubility of molybdenum and significantly reduce yellow phase formation and $[9,10]$. The objective of the present work was to investigate the structural role of $\mathrm{Mo}$ and $\mathrm{V}$ in such glasses and any indications of interactions between these species as part of an effort to improve the understanding of the mechanism of action of this beneficial role of vanadium. X-ray absorption spectroscopy (XAS) and Raman spectroscopy can provide complementary information about atomic environments within glass structure and are used here to characterize the molybdenum and vanadium 
environments in these waste glasses. XAS is used here to determine valence and local structure around Mo and V while Raman can provide local and intermediate-range structural information around Mo in the glass structure.

Earlier Mo XAS studies [5,6,12,13] of silicate glasses synthesized under oxidizing environments, found Mo-O distances near $1.76 \AA$ in molybdate groups, but provided no further information beyond oxygen nearest-neighbors. Earlier Raman studies of Mo-containing silicate glasses [14] also indicated molybdate groups isolated from the silicate network and determined that molybdate Mo-O symmetrical stretch mode frequencies are sensitive to the network modifying cations in the glass. These mode frequency trends indicate that molybdate tetrahedra are surrounded by alkali or alkaline earth cations rather than being bonded directly to the borosilicate network in the glass structure (see Fig. 1 in [14]).

Mo can be found in two different valences in environments with coordinating oxygens: from molybdate tetrahedra $\left(\mathrm{Mo}^{6+} \mathrm{O}_{4}\right)$, in $\mathrm{CaMoO}_{4}$ (powellite) [15], $\mathrm{Li}_{2} \mathrm{MoO}_{4}$, and $\mathrm{Na}_{2} \mathrm{MoO}_{4}$ salts $[16,17]$, to distorted octahedra $\left(\mathrm{Mo}^{4+} \mathrm{O}_{6}\right)$, in crystalline $\mathrm{MoO}_{2}$ [18]. The molybdate environments in silicate glasses are quite different compared with those in the few Mo-silicate crystal structures that have been determined: $\mathrm{La}_{3} \mathrm{Mo}_{4} \mathrm{SiO}_{14}$ and $\mathrm{Mo}_{4} \mathrm{P}_{6} \mathrm{Si}_{2} \mathrm{O}_{25}$ [19,20], where Mo is found in six-coordinated sites with Mo-O distances ranging from 1.93 to $2.17 \AA$. In $\mathrm{Mo}_{4} \mathrm{P}_{6} \mathrm{Si}_{2} \mathrm{O}_{25}$, the $\mathrm{MoO}_{6}$ sites are not bonded directly to $\mathrm{SiO}_{4}$ tetrahedra but to $\mathrm{PO}_{4}$ tetrahedra. In $\mathrm{La}_{3} \mathrm{Mo}_{4} \mathrm{SiO}_{14}$, the $\mathrm{MoO}_{6}$ groups polymerize with themselves by sharing two oxygen atoms, while bonding to $\mathrm{SiO}_{4}$ tetrahedra through an elongated Mo-O distance of $2.14 \AA$. 
Vanadium can be found in three different valences and environments with coordinating oxygens: from vanadate $\left(\mathrm{V}^{5+} \mathrm{O}_{4}\right)$ tetrahedra, in $\mathrm{Pb}_{5}\left(\mathrm{VO}_{4}\right)_{3} \mathrm{Cl}$ (vanadinite) [21], to fivecoordinated $\mathrm{V}^{4+} \mathrm{O}_{5}$, in cavansite $\left(\mathrm{Ca}(\mathrm{VO}) \mathrm{Si}_{4} \mathrm{O}_{10} 4\left(\mathrm{H}_{2} \mathrm{O}\right)\right)$ [22], to octahedrally coordinated $\mathrm{V}^{3+} \mathrm{O}_{6}$, in roscoelite $\left(\mathrm{K}(\mathrm{V}, \mathrm{Mg}, \mathrm{Al})_{2} \mathrm{AlSi}_{3} \mathrm{O}_{10}(\mathrm{OH})_{2}\right)$ [23]. Vanadium XAS studies of silicate glasses [24-27], indicate predominantly vanadate sites with minor $\mathrm{V}^{4+} \mathrm{O}_{5}$ populations; weak $\mathrm{V}$-Si second nearest-neighbor correlations are seen in the $\mathrm{V}$ partial radial distribution functions (RDFs) of some glasses, which may indicate that some $\mathrm{VO}_{4}$ tetrahedra are linked to the silicate tetrahedral network.

\section{Experimental}

\subsection{Waste Glasses}

The 44 glasses measured for this study are in two groups: special-waste composition glasses and base-waste composition glasses. The special waste composition glasses include three simplified composition glasses where all of the network-modifying cations were replaced by Li (Li-Glass), Na (Na-Glass), or K (K-Glass) (Table S1); this was done to verify the Mo-O stretch mode frequency coupling behavior seen in previous work [14]. The $\mathrm{MoO}_{3}$ concentrations in the other special waste glasses range from being similar to nearly $50 \%$ higher with respect to the 
typical 1.2 to $1.5 \mathrm{wt} \% \mathrm{MoO}_{3}$ loading in glasses in a related study [10]. The base waste glasses (Table S2) were synthesized in 12 series where the $\mathrm{MoO}_{3}$ content was systematically varied to concentrations considerably higher than those glasses in ref. [10]; this was done to test the limits of Mo solubility in the melt and resulting glass. The end of each base-waste glass sample name lists the $\mathrm{MoO}_{3}$ content (for example, Base-10-Mo2.26 contains 2.26 wt. $\% \mathrm{MoO}_{3}$ ). Other groupings of base glasses can be compared where the $\mathrm{MoO}_{3}$ content remains relatively constant while the $\mathrm{V}_{2} \mathrm{O}_{5}$ concentration varies: in three base waste glass series $\mathrm{V}_{2} \mathrm{O}_{5}$ varies from 0 to near 5.24 wt.\% in glasses Base-10-Mo2.26, Base-11-Mo2.19, and Base-12-Mo2.12 (Table S2). Variations in the major network modifying cations $\mathrm{Li}$ and $\mathrm{Na}$ were also investigated, where $\mathrm{Li}_{2} \mathrm{O}$ varies from 0 to near 5 wt. \%, from 5 A-N6-G to S-N8-1, respectively (Table S1), and $\mathrm{Na}_{2} \mathrm{O}$ varies from 6.6 to near $17.2 \mathrm{wt} . \%$, from Base-5-Mo2.30 (Table S2) to 5A-N6-G, respectively. The glass 5A-N6-G has the lowest $\mathrm{MoO}_{3}$ content of all of the glasses investigated (near 1.0 wt.\%). $\mathrm{MoO}_{3}$ was also varied from certain base waste glass compositions, such as Base-4Mo2.38 (2.38 wt.\%) to a corresponding Mo-enriched glass Base-4-Mo6.38 (6.38 wt.\%). The base waste glass compositions also include lanthanides: $\mathrm{Gd}_{2} \mathrm{O}_{3}$ near 1.8 wt. $\%, \mathrm{Nd}_{2} \mathrm{O}_{3}$ near 2.7 wt.\%, and $\operatorname{Pr}_{6} \mathrm{O}_{11}$ near 0.8 wt.\%. 


\subsection{X-ray Absorption Spectroscopy}

Mo and V K-edge XAS were measured for four crystalline standards and 13 representative glasses. Two crystalline Mo standards were used: $\mathrm{MoO}_{2}$ (Apache Chemical) containing $\mathrm{Mo}^{4+}$ within linked $\mathrm{MoO}_{6}$ sites [18] and powellite $\left(\mathrm{CaMoO}_{4}\right)(\mathrm{NMNH} \# 174384$, from India) containing $\mathrm{Mo}^{6+}$ within molybdate tetrahedra [15]. The two crystalline $\mathrm{V}$ standards used were: vanadinite $\left(\mathrm{Pb}_{5}\left(\mathrm{VO}_{4}\right)_{3} \mathrm{Cl}\right)\left(\mathrm{NMNH} \# \mathrm{C} 5605\right.$, from Arizona), containing $\mathrm{V}^{5+}$ within vanadate tetrahedra [21]) and cavansite $\left(\mathrm{Ca}(\mathrm{VO}) \mathrm{Si}_{4} \mathrm{O}_{10} \cdot 4\left(\mathrm{H}_{2} \mathrm{O}\right)\right.$ (NMNH \#R19353, from India), containing $\mathrm{V}^{4+}$ within $\mathrm{VO}_{5}$ groups [22]). Phase identification of each standard was verified by powder X-ray diffraction (XRD). Glass fragments used for XAS were taken from homogeneous portions of the annealed melt material. Most of the waste glasses contained minor amounts of $\mathrm{Pd}$ metal, $\mathrm{RuO}_{2}$, and $\mathrm{RhO}_{2}$. All samples were ground and sieved; one layer of sample particles was deposited on transparent tape. The XAS samples have average particle sizes that are approximately one to two absorption lengths thick at the Mo or V K-edge energy.

The XAS data (Figs. 1, and S1-S4) were collected on Beam Line X23-A2 at the National Synchrotron Light Source (NSLS), Brookhaven National Laboratory, Upton, NY, where synchrotron conditions were near $250 \mathrm{~mA}$ and $2.8 \mathrm{GeV}$. Incident beam slits, down-stream of the Si (311) double-crystal monochromator, were set to $0.5 \mathrm{~mm}$ x $9 \mathrm{~mm}$, resulting in an energy resolution near $3 \mathrm{eV}$ for the Mo K-edge XAS and $1 \mathrm{eV}$ for the V K-edge XAS. The Mo K-edge spectra were gathered so that the monochromator was scanned from 19,900 to $20,700 \mathrm{eV}$, which 
included the Mo K-absorption edge near 20,000 eV. For the V XAS data, the monochromator was scanned over a narrow energy range from 5330 to $5620 \mathrm{eV}$, which included only the V Kabsorption edge near $5465 \mathrm{eV}$. Only V XANES data were collected because the waste glasses contain $\mathrm{La}, \mathrm{Ba}, \mathrm{Cs}, \mathrm{Ce}$, and $\mathrm{Pr}$, where the L-edges for these elements are superimposed on the $\mathrm{V}$ EXAFS features. The incident $\mathrm{I}_{0}$, transmitted $\left(\mathrm{I}_{\mathrm{t}}\right)$, and reference $\left(\mathrm{I}_{\mathrm{r}}\right) \mathrm{X}$-ray intensities were measured using three ion chambers. If from the sample was measured by a four-element $\mathrm{Si}$ drifted solid-state detector [28]. The axis of the solid-state detector was positioned perpendicular with respect to the incident beam, while facing the flat sample tape placed at a $45^{\circ}$ angle with respect to the incident beam, and between the $\mathrm{I}_{0}$ and $\mathrm{I}_{\mathrm{t}}$ ion chambers. To calibrate the $\mathrm{V}$ or Mo $\mathrm{K}$-edge energy in each X-ray fluorescence spectrum, the transmission reference spectrum of $\mathrm{V}$ or Mo foil (where $\mu=-\ln \left(\mathrm{I}_{\mathrm{r}} / \mathrm{I}_{\mathrm{t}}\right)$ ) was measured simultaneously with each sample run, where the foil was placed between the $I_{t}$ and $I_{r}$ ion chambers down-stream of the sample. XANES and EXAFS data analysis details are included in Supplementary Information, Section S1.

\subsection{Raman Spectroscopy}

Raman data were collected on 44 Mo-borosilicate glasses (Figs. 2-7). The spectra were gathered from points in the glass free of any opaque metal or oxide phases. Two crystalline standards measured were: $\mathrm{Na}_{2} \mathrm{MoO}_{4}$, which contains isolated molybdate tetrahedra surrounded 
by $\mathrm{Na}^{+}[29]$, and $\mathrm{LiMg}_{3} \mathrm{VMo}_{2} \mathrm{O}_{12}$, which has isolated vanadate tetrahedra surrounded by $\mathrm{Li}^{+}$ and $\mathrm{Mg}^{2+}[30]$.

A single grating spectrograph - notch filter micro-Raman system [31] was used to gather the spectra. A Melles-Griot Model $45 \mathrm{Ar}^{+}$laser provided the $5145 \AA$ wavelength incident light that was directed through a broad band polarization rotator (Newport Model PR-550) to the laser microscope which guided the laser light down to the sample surface through a long working distance Mitutoyo 10x microscope objective. The laser-light was focused to a $10 \mu \mathrm{m}$ diameter spot, where power levels were approximately $18 \mathrm{~mW}$ at the sample. Room temperature polarized spectra were gathered in back-scattering geometry. The scattered light was directed through an analyzer polarizer in the microscope column that was set to one orientation for all polarized spectra collected. After the analyzer, the scattered light proceeded through holographic notch and super-notch filters (Kaiser Optical Systems), which reduced the Rayleigh (or elastically) scattered light intensity by ten optical densities. The notch filters were oriented in the scattered light path so that the filter cut-off frequency was minimized to near $70 \mathrm{~cm}^{-1}$ from the laser line $(0$ $\mathrm{cm}^{-1}$ in the spectra presented here). The spectrograph used a $1200 \mathrm{gr} / \mathrm{mm}$ grating (Richardson Grating Laboratory) that was set to disperse the Stokes scattered light from the sample on to a 2048 x 512 element Peltier cooled CCD detector Andor Technology (Model DU440BV). Due to the relatively broad spectral features for most samples measured, the incident slits of the JY-Horiba HR460 spectrograph were set to $6 \mathrm{~cm}^{-1}$ resolution for the $1200 \mathrm{gr} / \mathrm{mm}$ grating to collect spectra from 50 to $1600 \mathrm{~cm}^{-1}$. The spectrograph was frequency calibrated using $\mathrm{CCl}_{4}$, so 
that the recorded frequencies are accurate to within $\pm 1 \mathrm{~cm}^{-1}$. Parallel-polarized (VV) or crosspolarized (HV) spectra were collected, where the incident laser light was vertically or horizontally polarized, respectively, as it entered the microscope.

Each spectrum presented is an average of 30 exposures, collected at 10 seconds each. A blank spectrum was collected using the same collection parameters, where the incident laser light was blocked; this recorded any spectral contributions from the system. The blank data were then subtracted from each spectrum gathered for the samples so that the resulting difference spectra (presented in Figs. 2,3,5,7) have contributions from the sample only.

The frequency of the molybdate $v_{1}$ Mo-O stretch mode near $900 \mathrm{~cm}^{-1}$ in the glass spectra was determined in two different ways, depending on the complexity of the Raman spectral features from 750 to $1200 \mathrm{~cm}^{-1}$. Where these higher frequency features are dominated by the Mo-O stretch mode (Fig. 3), the mode frequency was simply measured at the peak maximum. However, for the glasses that have the Mo-O stretch mode overlapping with other significantly large features, such as the vanadate tetrahedral $v_{1} \mathrm{~V}-\mathrm{O}$ stretch mode near $865 \mathrm{~cm}^{-1}$, the overlap itself can cause an apparent shift of the Mo-O mode peak frequency (Fig. 5). To better determine the actual frequency of the Mo-O stretch mode for the 18 base glasses that have these mode overlap issues, Raman features from 750 to $1200 \mathrm{~cm}^{-1}$ were fit with Gaussian peaks using the program IGOR [32]. The frequency at the centroid of the Gaussian peak that corresponds to the Mo-O stretch mode peak is listed as $v_{1}$ for these glasses (Table S2). 
Heating experiments on crystalline $\mathrm{Na}_{2} \mathrm{MoO}_{4}$ were done to observe spectral changes upon melting and to see how Mo-O stretch modes compare with those for the glasses measured. Powder fragments were placed on a Pt foil within a Linkam model TS1500 heating stage. Experimental details are included in Supplementary Information, Section S2.

\section{Discussion}

\subsection{X-ray Absorption Spectroscopy}

\subsubsection{Vanadium XANES}

XANES data collected for the standards vary significantly from tetrahedral $\mathrm{V}^{5+} \mathrm{O}_{4}$ in vanadinite to penta-coordinated $\mathrm{V}^{4+} \mathrm{O}_{5}$ in cavansite (Fig. S1), and are nearly identical to the $\mathrm{V}$ XANES spectra of these compounds presented earlier [24-27]. The narrow edge feature near $5468 \mathrm{eV}$ is most prominent for tetrahedral $\mathrm{V}^{5+}$ in vanadinite, while the main edge shifts to lower energies for the more reduced penta-coordinated $\mathrm{V}^{4+}$ in cavansite.

V XANES data were collected for seven glasses: Base-5-Mo2.30, Base-5-Mo6.30, Base6-Mo2.23, Base-6-Mo6.23, Base-11-Mo2.19, Base-11-Mo4.19, and Base-12-Mo2.12), where $\mathrm{Li}_{2} \mathrm{O}, \mathrm{Na}_{2} \mathrm{O}, \mathrm{V}_{2} \mathrm{O}_{5}$, and $\mathrm{MoO}_{3}$ concentrations vary considerably (Table S2). The XANES data for all seven glasses (Fig. S1, red spectra) are nearly identical with respect to each other and are 
most similar to that for vanadinite. Any significant differences in the glass XANES are seen only between 5488 and $5493 \mathrm{eV}$, which are caused by different intensities of the La $\mathrm{L}_{\mathrm{III}}$-edge peak and reflect the different $\mathrm{La}_{2} \mathrm{O}_{3}$ concentrations in each glass. The sharp edge feature near 5468 $\mathrm{eV}$ in each glass spectrum is slightly different in shape and energy with respect to the equivalent feature for vanadinite, which may indicate slight $\mathrm{VO}_{4}$ tetrahedral distortions in the glasses compared with vanadate tetrahedra in vanadinite [26]. On the other hand, the glass V XANES spectra were fit by the program IFEFFIT $[34,35]$ using linear combinations of the XANES for the two standards to obtain percentages of $\mathrm{V}^{5+} \mathrm{O}_{4}$ and $\mathrm{V}^{4+} \mathrm{O}_{5}$ sites in each glass, as done earlier [25]. The fitting results indicate $\mathrm{V}^{5+} \mathrm{O}_{4}$ tetrahedra in all glasses measured, with possible minor amounts (5 to $8 \%$ ) of $\mathrm{V}^{4+} \mathrm{O}_{5}$ groups. Overall, the average local $\mathrm{V}$ environment in these glasses does not change perceptibly in response to the compositional changes.

\subsubsection{Molybdenum XANES}

The Mo XANES spectra for the two crystalline Mo-standards are also distinctly different. $\mathrm{Mo}^{6+}$ in molybdate tetrahedra within powellite has the narrow feature near $20,004 \mathrm{eV}$ and a higher edge energy with respect to the relatively simple edge for $\mathrm{Mo}^{4+} \mathrm{O}_{6}$ octahedra within $\mathrm{MoO}_{2}$ (Fig. S2). All glass spectra are nearly identical and most similar to the XANES for powellite (Fig. S2, red spectra). In general, the glass XANES have relatively broad features compared with powellite, which indicate more static disorder of the arrangement of atoms around Mo in the glasses than in powellite. The XANES for the glasses indicate that the Mo 
environments are dominated by oxidized $\mathrm{Mo}^{6+} \mathrm{O}_{4}$ tetrahedra, consistent with earlier findings for Mo in silicate glasses $[5,12]$.

\subsubsection{Mo EXAFS}

\subsubsection{Powellite Standard}

The $\mathrm{k}^{2} \chi(\mathrm{k})$ data and associated partial RDFs (Fourier transform of the k-weighted EXAFS data, or in this case, FT $\left.\mathrm{k}^{2} \chi(\mathrm{k})\right)$ for the powellite standard is shown in Fig. 1.. The FT $\mathrm{k}^{2} \chi(\mathrm{k})$ data show that the powellite data are dominated by the nearest neighbor Mo-O peak near $1.3 \AA$ (which corresponds to an actual distance of $1.76 \AA$, due to phase shift effects).

Fitting results for the powellite data (Table S3) describe the major features in the $\mathrm{k}^{2} \chi(\mathrm{k})$ data and corresponding partial RDFs (Fig. S3). The final fitting parameters are in reasonable agreement with the actual nearest neighbor distances and coordination numbers found in the crystal structure [15].

\subsubsection{Glasses}

The partial RDF data for the glasses measured are dominated by the nearest-neighbor peak near $1.3 \AA$ that closely corresponds with that for powellite (Fig. 1, red lines). By comparing the partial RDF data for the glasses with the powellite data, one can conclude that the Mo 
environments in the glasses are quite similar to the isolated $\mathrm{MoO}_{4}$ tetrahedra in powellite. There is no clear evidence of second or third-nearest-neighbor contributions in the glass partial RDF data compared with the Mo-O peak near $2.5 \AA$ as well as the Mo-O and Mo-Ca peak near $3.5 \AA$ in the powellite partial RDF.

The glass EXAFS fitting results indicate Mo-O distances that are statistically equivalent to the tetrahedral $1.76 \AA$ Mo-O distance in powellite (Fig. S4 and Tables S3 and S4). Except for two glasses, the coordination numbers are statistically equivalent to 4.0, also indicative of tetrahedral molybdate environments. The other two glasses, Na-glass and Base-10-Mo2,26, have larger coordination numbers and Debye-Waller factors than the other glasses and powellite, which probably indicates wider distributions of nearest-neighbor Mo-O distances within disordered molybdate tetrahedra. Overall, Mo EXAFS data and fitting results for all glasses measured show Mo in isolated $\mathrm{MoO}_{4}$ tetrahedra that do not change significantly with respect to glass chemistry. These findings are consistent with the earlier XAS studies of Mo in silicate glasses $[5,6,12]$.

\subsection{Raman Spectroscopy}

The Raman spectra of the borosilicate glasses measured are dominated by features from the borosilicate network [14,36] (Figs. 2, 3, 5 and 7). The broad envelope below $600 \mathrm{~cm}^{-1}$ is due to vibrations involving motions from $\mathrm{Si}-\mathrm{O}-\mathrm{Si}$ and larger atom groups such as rings of silicate tetrahedra linked with $\mathrm{BO}_{3}$ triangles and $\mathrm{BO}_{4}$ tetrahedra. More localized borosilicate network displacements, such as $\mathrm{Si}-\mathrm{O}$ stretch within silicate tetrahedra, dominate modes at frequencies 
between 850 and $1200 \mathrm{~cm}^{-1}$. The weak, broad feature near $1400 \mathrm{~cm}^{-1}$ is due to B-O stretch motions within $\mathrm{BO}_{3}$ triangles that are likely within the borosilicate network $[14,36]$.

The Raman spectra of borosilicate glasses can be sensitive to tetrahedral anions not bonded to the borosilicate network, but surrounded by network modifying cations. Examples of these environments in the borosilicate glasses investigated here include sulfate [36], vanadate [37], and molybdate tetrahedra [14]. The borosilicate networks have relatively small Raman scattering cross-sections [36]. However, isolated sulfate, vanadate, and molybdate tetrahedra have large Raman cross-sections that produce higher frequency T-O stretch $\left(v_{1}\right)$ and lower frequency O-T-O bend $\left(v_{2}\right)$ modes in the glass spectra, where, $\mathrm{T}=\mathrm{S}, \mathrm{V}$, or Mo (Figs. 2, 3, 5, and 7). Due to their large cross-sections, sulfate, vanadate, and molybdate Raman features typically stand out among the relatively weak borosilicate features, even at low $\mathrm{SO}_{3}, \mathrm{~V}_{2} \mathrm{O}_{5}$, or $\mathrm{MoO}_{3}$ concentrations. In view of the focus on the structural role of Mo in this study, the behavior of the molybdate modes is discussed more extensively below.

In crystalline molybdates and Mo-containing borosilicate glasses, molybdate-dependent features include the polarized Mo-O symmetric stretch mode near $900 \mathrm{~cm}^{-1}$ that is observed in the parallel-polarized spectra but which is absent or weak in the cross-polarized spectra. O-Mo-O bend modes near $330 \mathrm{~cm}^{-1}$ are observed in both parallel- and cross-polarized spectra. Raman spectra for the molybdate salts, $\mathrm{Li}_{2} \mathrm{MoO}_{4}$ [38] and $\mathrm{Na}_{2} \mathrm{MoO}_{4}$ (Fig. 2), have $v_{1}$ Mo-O stretch modes at 908 and $891 \mathrm{~cm}^{-1}$, respectively. Examples of these modes can be seen in the 
comparison of crystalline sodium molybdate and the simplified composition Na-glass (Fig. 2), where Mo-O stretch and O-Mo-O bend modes are shifted to higher frequencies for Na-glass.

The Mo-O stretch mode frequency $\left(v_{1}\right)$ can shift depending on the network modifying cation-type. This is clearly seen for Li-, Na-, and K-glasses (Fig. 3), where $v_{1}$ as well as peak widths steadily increase as the network modifying cation changes from $\mathrm{K}$ to $\mathrm{Na}$ to $\mathrm{Li}$. Similar to what was found for sulfate in waste glasses [36], a relationship between $v_{1}$ versus average network modifying cation charge density is evident (Figs. 4 and 6). Typical waste glass chemistry in this study contains over seven network modifying alkali and alkaline earth cations that change proportions from one glass series to another. Therefore, the average charge density was calculated considering each network modifier ion type in the glass chemistry. Initially, the charge density for each network modifier in the glasses, $\mathrm{Li}^{+}, \mathrm{Na}^{+}, \mathrm{Rb}^{+}, \mathrm{Cs}^{+}, \mathrm{Sr}^{2+}$, or $\mathrm{Ba}^{2+}$, was determined from the valence of each cation divided by the spherical volume calculated from the effective ionic radius of that cation [39]. By using the glass composition in mol.\%, a weighted mean network modifying cation charge density can then be calculated (Tables S1 and S2). For most waste glasses studied, $\mathrm{Na}$ and $\mathrm{Li}$ have a greater than $90 \%$ influence on the weighted mean charge density for each glass.

The $v_{1}$ Mo-O stretch mode frequency increases somewhat linearly with respect to the average charge density for the three simplified composition glasses (Fig. 4). The same relationship is also followed for the special- and base-waste glasses measured, where $v_{1}$ versus 
charge density points for glasses having network-modifying cations dominated by $\mathrm{Li}$ and $\mathrm{Na}$ are found between those for Li-glass and Na-glass. Similar observations were made earlier by Caurant et al. [14] for Si-Na-Mo and Si-Ca-Mo-silicate glasses, where $v_{1}$ frequencies for those glasses (also plotted in Fig. 4) follow the general trend for the glasses measured here. The S-series glasses have approximately $3.3 \mathrm{wt} . \% \mathrm{CaO}$ (Table $\mathrm{S} 1$ ); correspondingly, their points cluster near the Si-Ca-Mo glass [14] (Fig. 4) that has only $\mathrm{Ca}^{2+}$ network modifying cations.

In general, the O-Mo-O bend peak mode frequencies and shapes are hard to compare and quantify for the glasses investigated, especially when similar frequency O-V-O bend modes appear with the addition of $\mathrm{V}_{2} \mathrm{O}_{5}$ to the glass chemistry. The O-V-O modes, typically centered near $370 \mathrm{~cm}^{-1}$, overlap with the high frequency shoulder of the O-Mo-O bend modes near 325 $\mathrm{cm}^{-1}$ (Fig. 5).

Most glasses measured for this study contain lanthanides that produce high intensity luminescence features above $1600 \mathrm{~cm}^{-1}$. Therefore, what appears to be an increasing background at frequencies greater than $1500 \mathrm{~cm}^{-1}$ (Fig. 5), is actually the low frequency shoulder of a broad luminescence band centered near $1690 \mathrm{~cm}^{-1}$. These features are not present in the spectra of glasses that are free of rare earth elements, as seen for the Li-, Na-, and K-glasses (Fig. 3).

\subsubsection{Vanadium Influence on the Glass Raman Spectra}


Introduction of $\mathrm{V}_{2} \mathrm{O}_{5}$ to the glass adds vanadate $v_{1} \mathrm{~V}-\mathrm{O}$ stretch modes near $865 \mathrm{~cm}^{-1}$ and $v_{2} \mathrm{O}-\mathrm{V}-\mathrm{O}$ bend modes near $370 \mathrm{~cm}^{-1}$ to the spectra (Fig. 5). Raman intensities of these vanadate features increase as the $\mathrm{V}_{2} \mathrm{O}_{5}$ content in the glass increases while the $\mathrm{MoO}_{3}$ content remains similar for various glass groupings: for example, Base-10-Mo2.26 with 0 wt. $\% \mathrm{~V}_{2} \mathrm{O}_{5}$, Base-11Mo2.19 with 2.61 wt.\% $\mathrm{V}_{2} \mathrm{O}_{5}$, and Base-12-Mo2.12 with 5.22 wt.\% $\mathrm{V}_{2} \mathrm{O}_{5}$ (Fig. 5, Table S2). These observations are consistent with the V XANES findings that determined more than $90 \%$ of the vanadium in these glasses is in vanadate tetrahedra.

For these glass groups, the $v_{1}$ Mo-O stretch mode frequency can decrease by as much as $7 \mathrm{~cm}^{-1}$ as the $\mathrm{V}_{2} \mathrm{O}_{5}$ content increases (Figs. 4 and 5; Table S2). This indicates that for some glasses measured, environments surrounding the $\mathrm{MoO}_{4}$ tetrahedra are changing enough with the addition of $\mathrm{V}_{2} \mathrm{O}_{5}$ to affect internal molybdate modes.

Unfortunately, the $\mathrm{V}-\mathrm{O} v_{1}$ frequency cannot be clearly determined for many V-containing glasses investigated. For a number of glasses, this mode is only a shoulder on the dominant Mo-O stretch mode that is also superimposed on various Q-species Si-O stretch modes.

\subsubsection{Molybdenum Influence on the Glass Raman Spectra}


By increasing the $\mathrm{MoO}_{3}$-content in the glasses, the Mo-O stretch $v_{1}$ mode frequencies also decrease for nine base glass series (Table S2). The Mo-O stretch $v_{1}$ frequency does not change significantly for each of the remaining Base-5, Base-7, and Base-12 glass series (Table S2). These trends (Fig. 6) indicate that the base glasses can be divided into two groups: $\mathrm{Na}_{2} \mathrm{O}-$ poor $(6.6 \mathrm{wt} . \%)$, where the $v_{1}$ distribution is at a higher frequency range, and $\mathrm{Na}_{2} \mathrm{O}$-rich $(10.6$ wt.\%), where the $v_{1}$ distribution is at a lower frequency range. This $\mathrm{Na}_{2} \mathrm{O}$-based grouping follows the overall $v_{1}$ versus charge density trends for all glasses based on alkali and alkaline earth cation content. The $\mathrm{MoO}_{3}$-poor glass $v_{1}$ frequencies mostly cluster in the upper frequency end, while the $\mathrm{MoO}_{3}$-rich glass $v_{1}$ frequencies mostly cluster in the lower frequency end of these two distributions. This Mo-O $v_{1}$ shift to lower frequencies with increasing $\mathrm{MoO}_{3}$ content also parallels the $v_{1}$ trend between Na-Glass and crystalline $\mathrm{Na}_{2} \mathrm{MoO}_{4}$ (Figs. 2 and 6).

The Mo-O stretch $v_{1}$ frequency for molten $\mathrm{Na}_{2} \mathrm{MoO}_{4}$ is lower than that observed for both Na-Glass and crystalline $\mathrm{Na}_{2} \mathrm{MoO}_{4}$ (Figs. 2, 4, and 6). This shows that molybdate environments in Na-Glass, at least, can be considered different than $\mathrm{Na}_{2} \mathrm{MoO}_{4}$ melt surrounded by the borosilicate network. The higher Mo-O stretch $v_{1}$ frequencies for the glasses likely indicate stronger coupling around the molybdate tetrahedra possibly from fewer ionically bonded $\mathrm{Na}^{+}$or $\mathrm{MoO}_{4}{ }^{2-}$ that may be caused by influences from the more rigidly bonded borosilicate network. 


\section{Conclusions}

XAS information obtained for the Mo and V environments in these glasses provides only very localized structural details and indicates predominantly oxidized tetrahedral environments for both elements. The Mo EXAFS data sense only nearest-neighbor oxygens around Mo, with Mo-O distances near $1.76 \AA$, indicating significant positional disorder of the atoms external to tetrahedral $\mathrm{MoO}_{4}$. V XANES fitting of the glass data confirms that V populations are dominated by tetrahedral $\mathrm{V}^{5+} \mathrm{O}_{4}$ with possible minor amounts $(\leq 8 \%$ of all vanadium) of the reduced $\mathrm{V}^{4+} \mathrm{O}_{5}$ species. From the XAS evidence alone, no correlation can be seen between Mo and $\mathrm{V}$ in these glasses.

On the other hand, Raman spectroscopy provides limited longer-range information about the environments surrounding molybdate tetrahedra in these waste glasses. The molybdate Mo-O symmetrical stretch mode frequency $\left(v_{1}\right)$ for each glass is sensitive to the average charge density of the alkali and alkaline earth cations in the glass structure; this supports the model that $\mathrm{MoO}_{4}$ tetrahedra are surrounded by these cations $[5,14]$, especially Li and $\mathrm{Na}$, and are not bonded to the borosilicate network, as seen earlier for silicate glasses [5,6,12-14]. The $v_{1}$ frequency changes

can be as large as $10 \mathrm{~cm}^{-1}$, dependent on the different mix of network modifying cations in the 
waste glass chemistry. A secondary effect is also observed where the molybdate $v_{1}$ frequency can decrease by as much as $7 \mathrm{~cm}^{-1}$ with increasing $\mathrm{V}_{2} \mathrm{O}_{5}$ or $\mathrm{MoO}_{3}$ content in the glass.

These $v_{1}$-dependent trends indicate modifications of the environment around molybdate tetrahedra in the glass structure where vanadate and other molybdate anions may be replacing or affecting some of the network modifying $\mathrm{Li}$ and $\mathrm{Na}$ cations neighboring molybdate tetrahedra. These replacements may change the average charge density of nearest neighbor species to the molybdate tetrahedra. The $v_{1}$ frequency reductions with increasing $\mathrm{V}_{2} \mathrm{O}_{5}$ content indicate that $\mathrm{MoO}_{4}-\mathrm{Li}-\mathrm{VO}_{4}$ environments may exist in some of the more Li-rich waste glasses. Similar environments are found in vanadate-molybdate crystals, where $(\mathrm{Mo}, \mathrm{V}) \mathrm{O}_{4}$ tetrahedra share oxygen atoms with $(\mathrm{Li}, \mathrm{Mg}) \mathrm{O}_{6}$ octahedra and other six-coordinated Li, Mg-environments [30]. The Raman spectrum of $\mathrm{LiMg}_{3} \mathrm{VMo}_{2} \mathrm{O}_{12}$ has $\mathrm{V}-\mathrm{O}$ and $\mathrm{Mo}-\mathrm{O} v_{1}$ mode frequencies and relative intensities that are similar to those observed for one of the more $\mathrm{V}_{2} \mathrm{O}_{5}$-rich, Li-containing base waste glasses, Base-6-Mo6.23 (Fig. 7). The molybdate $v_{1}$ frequency reductions with increasing $\mathrm{MoO}_{3}$ or $\mathrm{V}_{2} \mathrm{O}_{5}$ content in the glass follow the same $v_{1}$ frequency trends between Na-glass and crystalline $\mathrm{Na}_{2} \mathrm{MoO}_{4}$, or Base-6-Mo6.23 glass and $\mathrm{LiMg}_{2} \mathrm{VMo}_{2} \mathrm{O}_{12}$, respectively. These observations suggest that as the $\mathrm{V}_{2} \mathrm{O}_{5}$ or $\mathrm{MoO}_{3}$ content increases in the glass, clustering of $\mathrm{MoO}_{4}$ tetrahedra with $\mathrm{VO}_{4}$ tetrahedra, and $\mathrm{MoO}_{4}$ tetrahedra with themselves, may be giving rise to structural precursors to crystalline molybdate-vanadate or $\mathrm{Na}_{2} \mathrm{MoO}_{4}$ phases. Thus it is 
possible that vanadate competes with the alkalis to form molydate clusters that are more dissimilar from the yellow phase structure, and therefore, less likely to promote its formation, Consequently, because of this clustering, the addition of vanadate would increase the number of molybdate tetrahedral sites per unit volume available in the glass structure and improve Mo solubility without causing yellow phase crystallization.

\section{Acknowledgments}

Funding for this study was provided, in part, by IHI Corporation and JNFL. We thank J.E. Post and P. Pohwat (Mineral Sciences Department, National Museum of Natural History, Smithsonian Institution) for supplying the powellite, vanadinite, and cavansite mineral samples, as well as L. Gillie (Department of Chemical and Biological Sciences, School of Applied Sciences, University of Huddersfield, UK) for providing the synthetic $\mathrm{LiMg}_{3} \mathrm{VMo}_{2} \mathrm{O}_{12}$ powder. We appreciate the help from J.C. Woicik (NIST) and George Sterbinsky (NSLS, NIST) for arranging the time at and assistance with NSLS Beam Line X23-A2. We also thank Mary Zischkau (VSL Summer Intern) for her assistance. 


\section{References}

[1] E. Schiewer, H. Rabe and S. Weisenburger, in Scientific Basis for Nuclear Waste Management V, Vol. 11, p 289, Materials Research Society (1982).

[2] R.S. Roth, J.R. Dennis, and H.F. McMurdie, in Phase Diagrams for Ceramists, Vol. VI, The American Ceramic Society, Inc. (1987).

[3] W. Lutze, in Radioactive Waste Forms for the Future, Edited by W. Lutze and R.C. Ewing, Elsevier Science Publishers B.V. (1988).

[4] R.J. Short, R.J. Hand, and N.C. Hyatt, Molybdenum in Nuclear Waste Glasses Incorporation and Redox State, in Scientific Basis for Nuclear Waste Management $X X V I$, vol. 757, p. 141 (2002).

[5] G. Calas, M. LeGrand, L. Galoisy, D. Ghaleb, J. Nuclear Materials, 322 (2003) 15-20.

[6] R.J. Short, R.J. Hand, N.C. Hyatt, G. Mobus, J. Nuclear Materials, 340 (2005) 179-186.

[7] O. Pinet, J.L. Dussossoy, C. David, and C. Fillet, Glass Matrices for Immobilizing Nuclear Waste Containing Molybdenum and Phosphorus, J. Nucl. Mat., 377, 307 (2008).

[8] I.L. Pegg, H. Gan, K.S. Matlack, Y. Endo, T. Fukui, A. Ohashi, I. Joseph and B.W. Bowan, Mitigation of Yellow Phase Formation at the Rokkasho HLW Vitification Facility, Paper 10107, Proc. Waste Management Symposium, Phoenix Arizona, USA. (2010). 
[9] H. Gan, K.S. Matlack, I.L. Pegg, I. Joseph, B.W. Bowan, Y. Miura, N. Kanehira, E. Ochi, T. Oniki, Y. Endo, Ceramics for Environmental and Energy Applications II: Ceramic Transactions, 46 (2014) 237-250,

[10] K.S. Matlack, H. Gan, I.L. Pegg, I. Joseph, B.W. Bowan, Y. Miura, N. Kanehira, E. Ochi, T. Oniki, Y. Endo, Ceramics for Environmental and Energy Applications II: Ceramic Transactions, 46 (2014) 225-235,

[11] I.L. Pegg, H. Gan, K.S. Matlack, Method for Vitrification of Waste, US Patent 9,245,655, Jan. 26, 2016.

[12] F. Farges, R. Siewert, G.E. Brown, Jr., A. Guesdon, and G. Morin, Canadian Mineral. 44 (2006) 731-753.

[13] R. J. Hand, R. J. Short, S. Morgan, N. C. Hyatt, G.Möbus, W.E. Lee, Glass Technology, $46: 2$ (2005) 121.

[14] D. Caurant, O. Majerus, E. Fadel, A. Quintas, C. Gervais, T. Charpentier, D. Neuville, J. Nuclear Materials, 396 (2010) 94-101.

[15] V.B. Aleksandrov, L.V. Gorbatij, V.V. Iljuhin, Kristallogr., SSSR, 13, (1967) 512-513.

[16] A.B. Barinov, R.K. Rastsvetaeva, Yu.V. Nekrasov, D.Yu. Pushcharovsky (2001) Dokl. Akad. Nauk, 376, 343-346.

[17] U. Kolitsch, Z. Kristallogr. Cryst. Mater. 216 (8) (2001) 449-454.

[18] R.W.G. Wyckoff, Crystal Structures (J. Wiley \& Sons, New York: 1965) v. 1 p. 258 (1963).

[19] P.W. Betteridge, A.K. Cheetham, J.A.K. Howard, G. Jakubicki, and W. H. McCarroll Inorg. Chem., 23 (1984) 737. 
[20] A. Leclaire, M. Lamire, B. Raveau (1988) Acta Cryst., C 44, 1181-1184.

[21] Y. Dai and J. Hugnes, Canad. Min., 27 (1989) 189.

[22] H.T. Evans, Am. Min., 58 (1973) 412.

[23] E.W. Heinrich, A.A. Levinson, Am. J. Sci. 253 (1955) 39.

[24] D. A. McKeown, I. S. Muller, K. S. Matlack, and I. L. Pegg, J. Non-Crystalline Solids, 298 (2002) 160 .

[25] D. A. McKeown, I.S. Muller, H. Gan, Z. Feng, C. Viraugh, and I. L. Pegg, J. NonCrystalline Solids, 357 (2011) 2735.

[26] J. Wong, F.W. Lytle, R.P. Messmer, and D.H. Maylotte, Phys. Rev. B., 30 (1984) 5596.

[27] G. Giuli, E. Paris, J. Mungall, C. Romano, and D. Dingwell, American Mineralogist, 89 (2004) 1640.

[28] J.C. Woicik, B. Ravel, D.A. Fischer, and W.J. Newburgh, J. Synchrotron Radiation, 17 (2010) 409.

[29] R.W.G. Wyckoff, Crystal Structures (J. Wiley \& Sons, New York: 1965) v. 3, p. 81.

[30] L.J. Gillie, S.A. deSouza, D. Sheptyakov, N. Reeves-McLaren, D. Pasero, A.R. West, J. Solid State Chem., 183 (2010) 2589.

[31] A.F. Goncharov and V.V. Struzhkin, J. Raman Spectroscopy, 34 (2003) 538.

[32] IGOR Pro version 6.31, WaveMetrics, Inc., Lake Oswego, OR 97035. 
[33] D.E. Sayers and B.A. Bunker in: X-ray Absorption Principles, Applications, Techniques of EXAFS, SEXAFS, and XANES, ed. D.C. Kroningsberger, R. Prins (Wiley, New York, 1988), Ch. 6, p. 211.

[34] B. Ravel and M. Newville, J. Synchrotron Radiation, 12 (2005) 537.

[35] M. Newville, J. Synchrotron Radiation, 8 (2001) 322.

[36] D.A. McKeown, I.S. Muller, H. Gan, I.L. Pegg, and C.A. Kendziora, J. Non-Crystalline Solids, 288 (2001) 191.

[37] D. Manara, A. Grandjean, O. Pinet, J.L. Dussossoy D.R. Neuville, J. of Non-Crystalline Solids 353 (2007) 12.

[38] O. Barinova, S. Kirsanova, A. Sadovskiy, and I. Avetissov, J. Crystal Growth, 401 (2014) 853.

[39] R.D. Shannon, Acta Cryst. A32 (1976) 751. 


\section{Figure Captions}

Fig. 1. Mo partial RDF (FT k ${ }^{2} \chi(\mathrm{k})$ ) data for the standards (line and points) and glasses (red lines). Important pair correlations from the crystal structure of the powellite standard are indicated. Peak positions are not corrected for phase shift effects.

Fig. 2. Parallel polarized spectra of Na-Glass containing only $\mathrm{Na}$ network modifying cations as well as $\mathrm{Na}_{2} \mathrm{MoO}_{4}$ crystal and melt.

Fig. 3. VV polarized Raman spectra of the simplified chemistry alkali series glasses containing one network modifying cation type. Molybdate Mo-O stretch $v_{1}$ and O-Mo-O $v_{2}$ bend mode frequencies are indicated. Spectra are offset for clarity.

Fig. 4. Molybdate Mo-O stretch $v_{1}$ frequency versus average network modifying cation charge density for the simplified glasses (open points: Li-glass, Na-glass, and K-glass) and base waste glasses (unlabeled black, green, and orange points) including four series, where $\mathrm{V}_{2} \mathrm{O}_{5}$ content is varied. $\mathrm{Na}$ and $\mathrm{Ca}$ network modifying cation $\mathrm{Si}-\mathrm{Na}-\mathrm{Mo}$ glass and $\mathrm{Si}-\mathrm{Ca}-\mathrm{Mo}$ glass, respectively, are from ref. [13]. $\mathrm{Na}_{2} \mathrm{MoO}_{4}$ crystal and melt are plotted as a blue cross and red point, respectively. Some glass names and series are indicated. 
Fig. 5. VV polarized Raman spectra of a base glass vanadium series, all with similar $\mathrm{MoO}_{3}$ content (Base-10-Mo2.26 (black), Base-11-Mo2.19 (green), and Base-12-Mo2.12 (red)) showing molybdate, sulfate, and vanadate $v_{1}(\mathrm{~T}-\mathrm{O})$ and $v_{2}(\mathrm{O}-\mathrm{T}-\mathrm{O})$ modes, where $\mathrm{T}=\mathrm{V}, \mathrm{Mo}$, or $\mathrm{S}$. Inset is detail of the Mo-O stretch $v_{1}$ modes and frequency behavior with respect to increasing $\mathrm{V}_{2} \mathrm{O}_{5}$ content.

Fig. 6. Mo-O $v_{1}$ stretch frequency versus network modifying cation charge density for base glass series where $\mathrm{MoO}_{3}$ content is varied. The distributions for two sets of glasses are based on different $\mathrm{Na}_{2} \mathrm{O}$ concentrations (indicated). Conventions in Fig. 4 are followed.

Fig. 7. VV polarized Raman spectra comparison of crystalline $\mathrm{LiMg}_{3} \mathrm{VMo}_{2} \mathrm{O}_{12}$ powder and Base-6-Mo6.23 glass with higher $\mathrm{MoO}_{3}$ and $\mathrm{V}_{2} \mathrm{O}_{5}$ content (Table S2). Upper right drawing is a $\mathrm{VO}_{4}-\mathrm{Li}-\mathrm{MoO}_{4}$ cluster in crystalline $\mathrm{LiMg}_{3} \mathrm{VMo}_{2} \mathrm{O}_{12}[30]$. T-O $v_{1}$ stretch mode frequencies are indicated (where $\mathrm{T}=\mathrm{V}$ or Mo). 


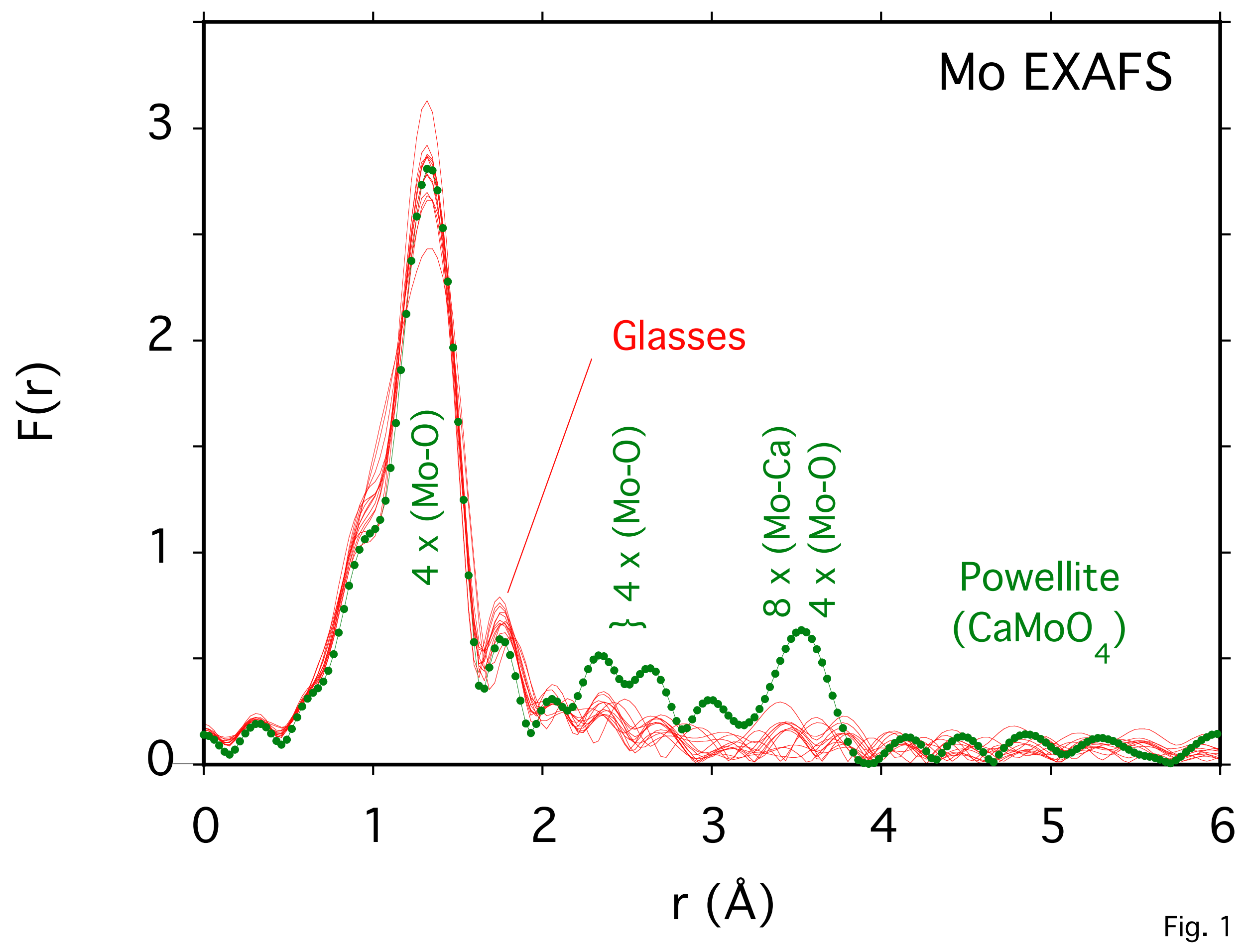




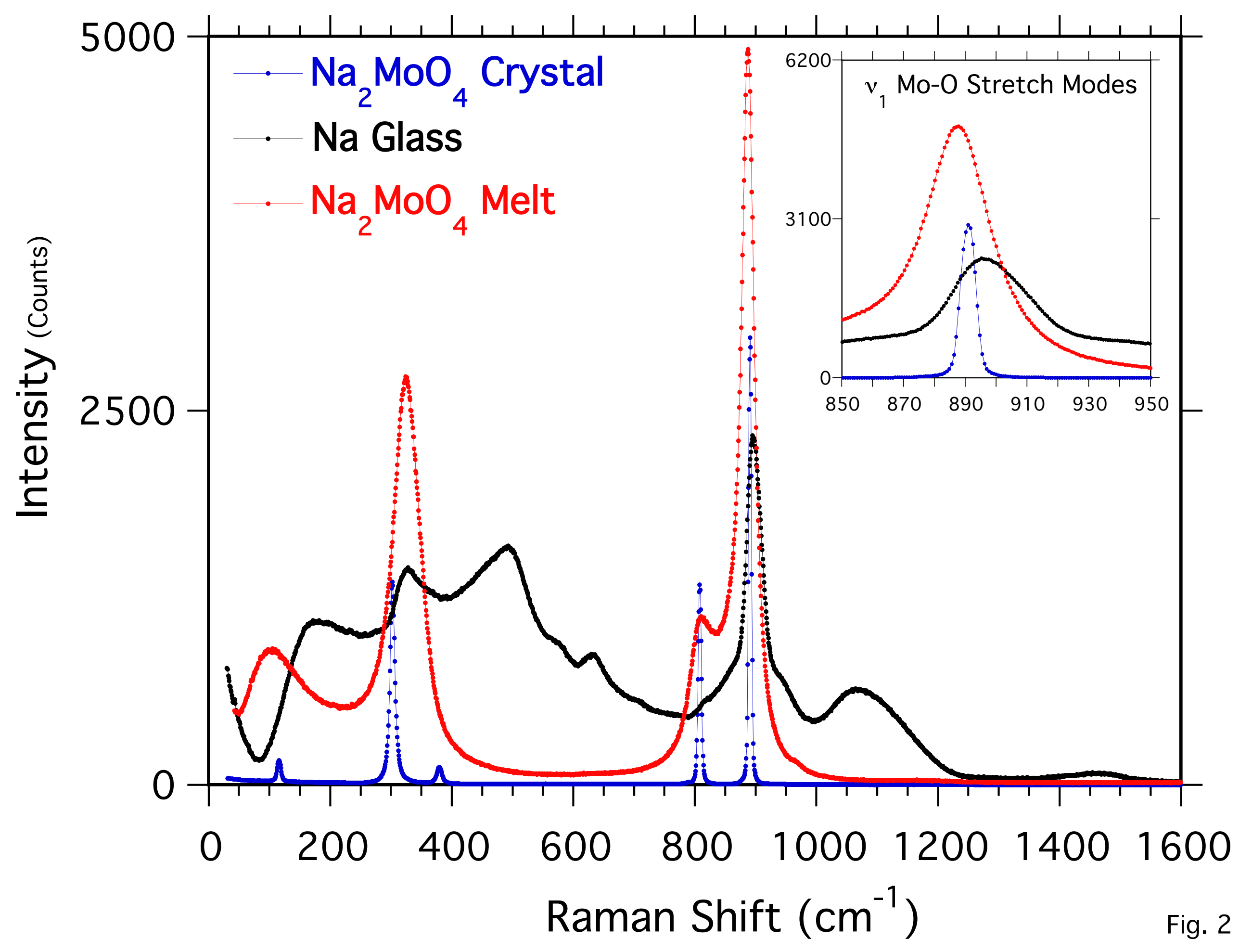




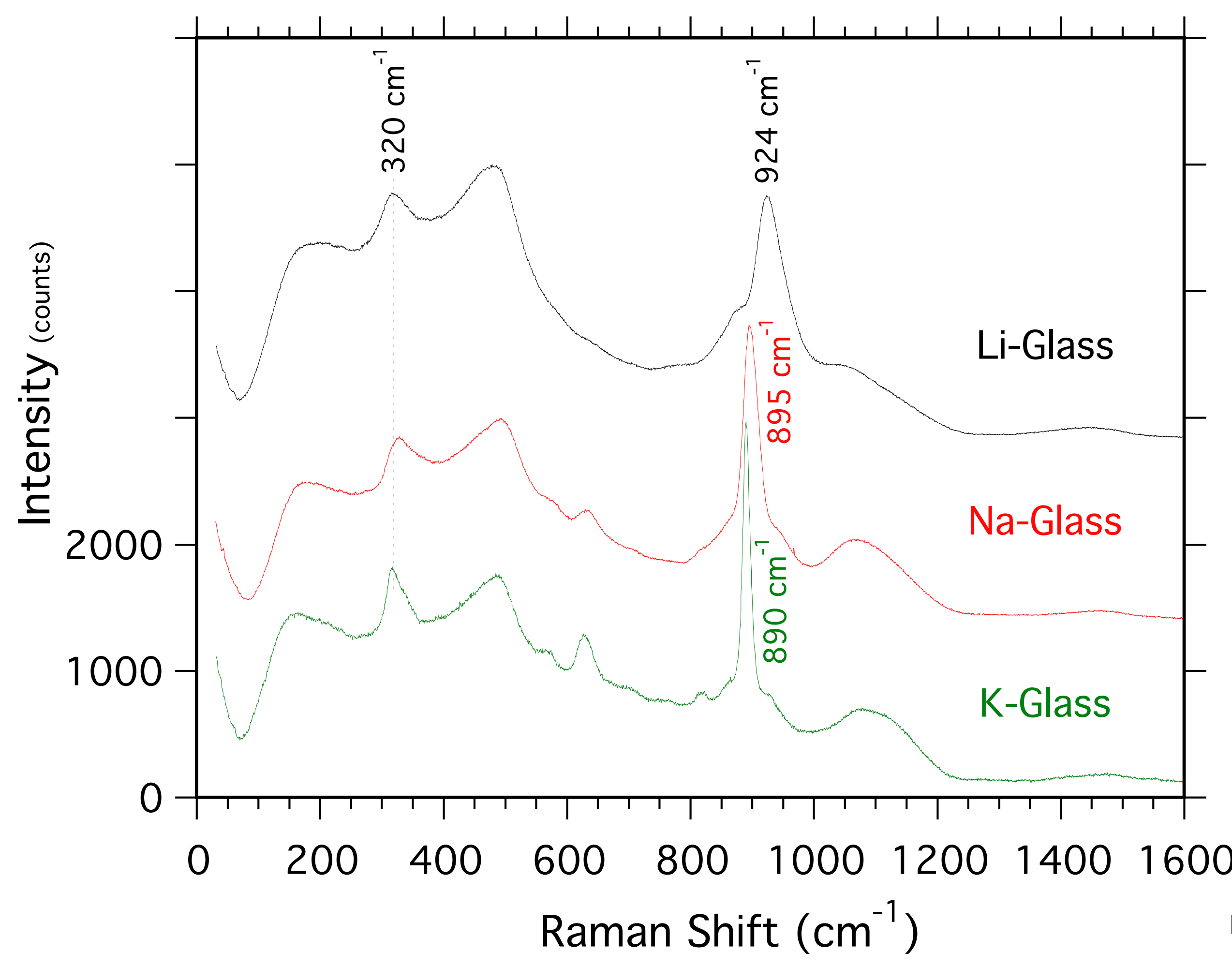

Fig. 3 


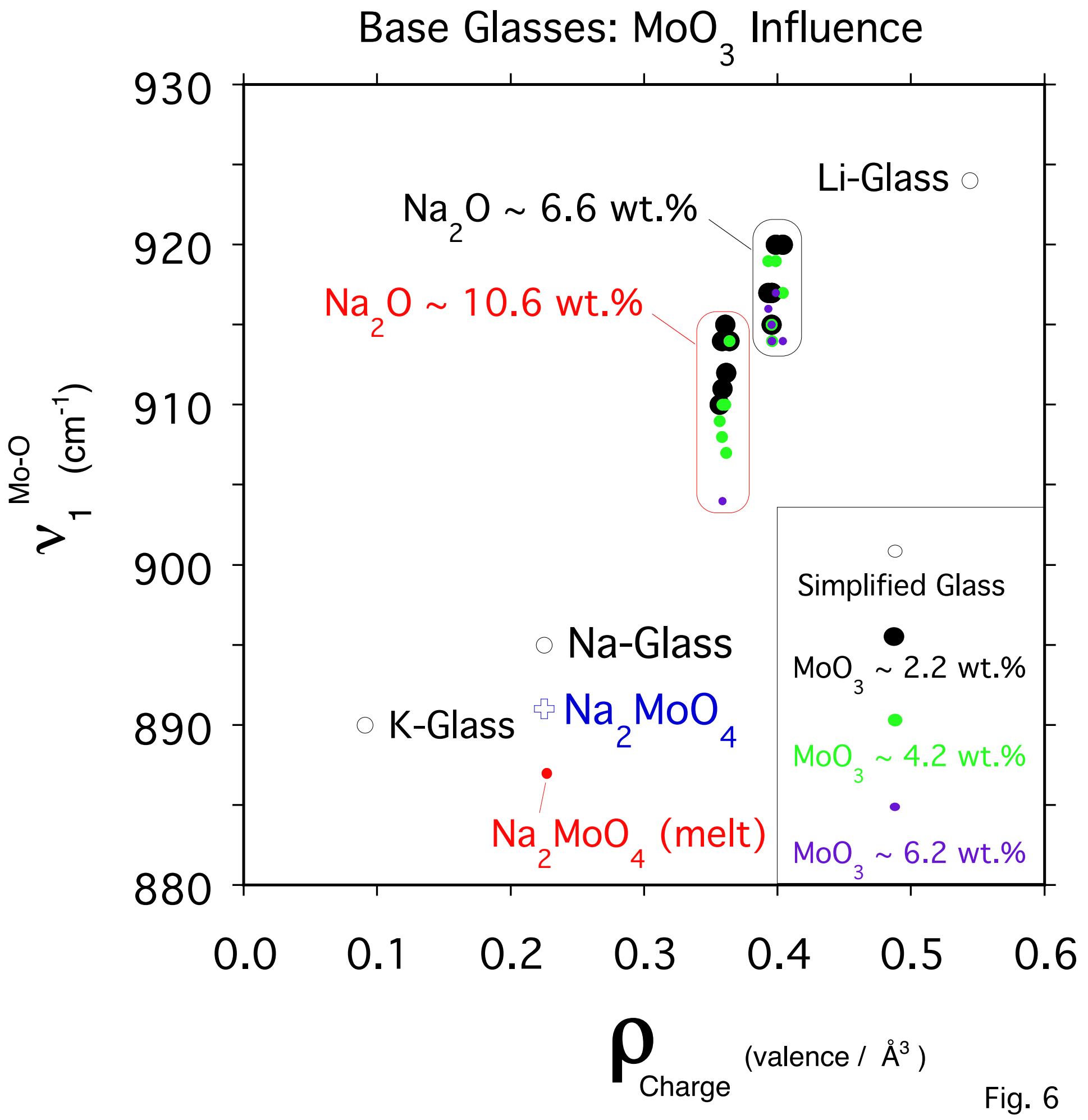




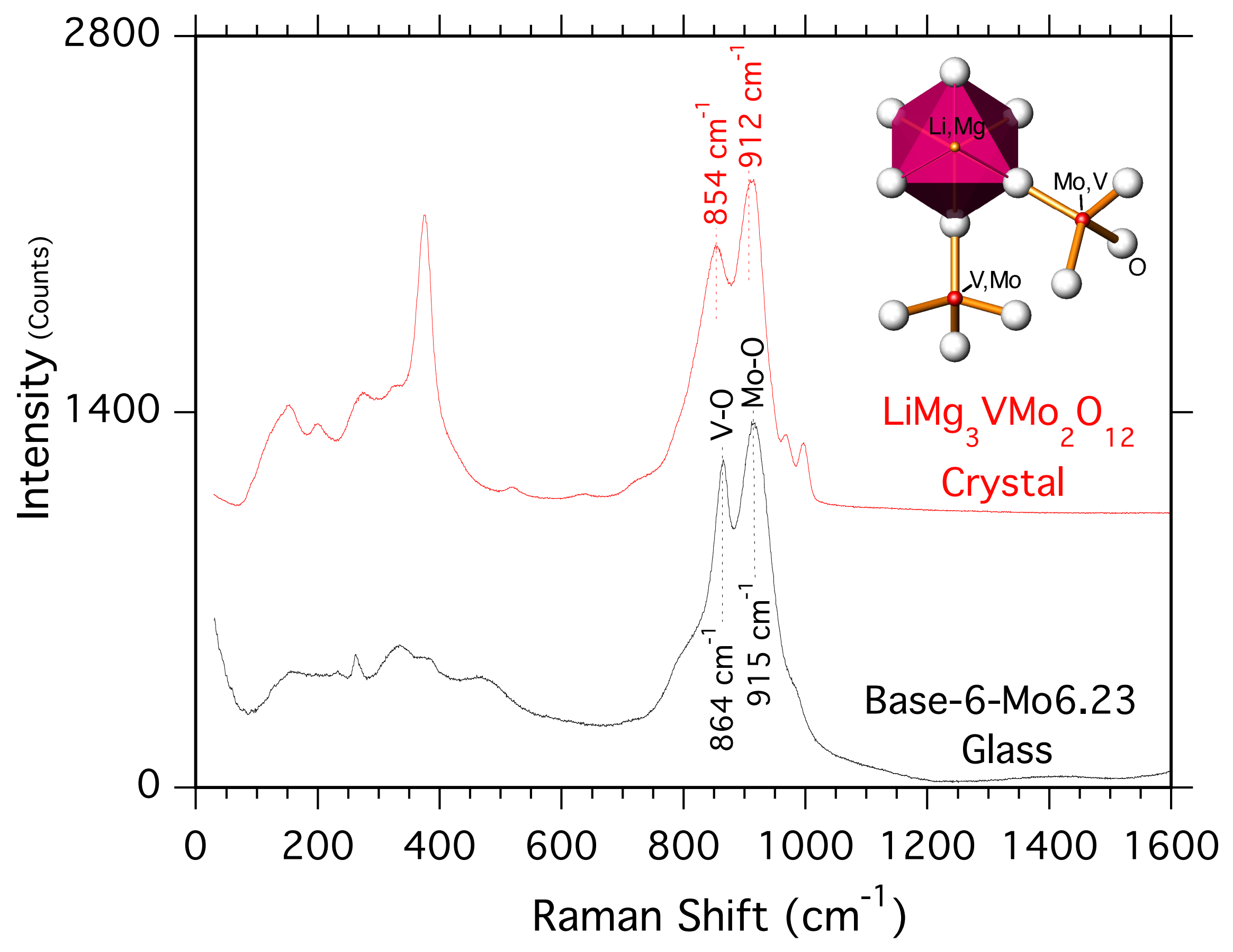

Fig. 7 